\title{
Pricing Credit Derivatives with Rating Transitions ${ }^{1}$
}

\author{
Viral V. Acharya \\ New York University \\ Stern School of Business \\ New York, NY 10012 \\ vacharya@stern.nyu.edu
}

\author{
Sanjiv Ranjan Das \\ Santa Clara University \\ 500 El Camino Drive \\ Santa Clara, CA 95053 \\ srdas@cs.berkeley.edu
}

\author{
Rangarajan K. Sundaram \\ New York University \\ Stern School of Business \\ New York, NY 10012 \\ rsundara@stern.nyu.edu
}

JEL Classification: G12, G13

Keywords: Risky Debt, Rating Transitions, Credit Derivatives, Credit Sensitive Note, HJM Model

November 5, 2001

Forthcoming in: Financial Analysts Journal

\footnotetext{
${ }^{1}$ The program code presented in this paper is intended only as pseudo-code and implemented versions may be undertaken at the user's risk. We would like to thank an anonymous referee whose suggestions have improved the exposition in the paper.
} 


\title{
Pricing Credit Derivatives with Rating Transitions
}

\author{
Digest
}

In recent years, "reduced form models" of pricing risky debt-financial engineering models that attempt to directly describe the arbitrage-free evolution of risky debt values, without reference to an underlying firm value process-have resulted in successful conjoint implementations of term structure models with default models. The current paper contributes to this literature by presenting a discrete-time reduced-form model for valuing risky debt based on an expansion of the term-structure model of Heath, Jarrow, and Morton (1990).

As in Das and Sundaram (2000), we expand the HJM model to include risky debt by adding a "forward spread" process to the forward rate process for (default-)risk-free bonds. Das and Sundaram (2000) only considered a single class of defaultable debt. The current paper generalizes that to allow for multiple classes of risky debt, and calibrates the arbitrage-free movement of all ratings classes on the same pricing lattice. Embedding all rating categories on one pricing lattice requires conditions ensuring consistency across all classes of debt. The additional information required to engineer this comes from the introduction of the rating transition matrix. Thus, in our model, we are now able to price credit derivatives based on multiple classes of debt, which was not possible using simpler models.

To understand the consistency conditions across rating classes, note that the credit rating of a corporate borrower can improve or deteriorate during the life of its issued debt. Thus, the credit spread on its debt contains information about the future credit spreads on debt of all possible rating classes that the borrower could migrate to. This is true for a corporate borrower with any given rating at a point of time. This interdependence of spreads across rating classes immediately implies that calibration of the forward spread process for a given rating class must be undertaken simultaneously with the calibration of the forward spread processes for all other rating classes. Formalizing this interdependence and characterizing the joint calibration process (Proposition 3.2) is the primary contribution of this paper.

One additional aspect of our approach is worth mentioning. For each rating class, instead of modeling the movement of the spread for that rating class directly, we focus on the process for inter-rating spreads, i.e., the spread for that class over the immediately superior ratings class. Thus, any credit spread is derived as the sum of the inter-rating spreads taken over all superior classes. This approach offers analytical tractability. No restrictions are placed on the correlation between these stochastic processes. The probability of default at any point in time is allowed to depend on the entire history of the process to that point, and is determined from rating transition matrices, exogenously supplied. The model is flexible to incorporate any specification for the recovery process that is consistent with the default process and the spread processes.

Our model requires as input the government yield curve. In addition, it also uses the term structures of 
credit spreads for each rating class, available from providers such as Bloomberg. The same source delivers required interest rate and spread volatilities. The model can be efficiently implemented and lends itself most appropriately to pricing of credit derivatives such as credit sensitive notes where the coupon payments are linked to credit quality of the underlying corporate borrower. We provide a numerical example to illustrate the calibration of the model and its use to price credit sensitive notes. 


\title{
Pricing Credit Derivatives with Rating Transitions
}

\begin{abstract}
We develop a model for pricing risky debt and valuing credit derivatives that is easily calibrated to existing variables. Our approach is based on expanding the Das and Sundaram (2000) extension of the HeathJarrow-Morton (1990) term-structure model to allow for multiple ratings classes of debt. The framework has two salient features: (i) it employs a ratings transition matrix as the driver or the default process, and (ii) the entire set of rating categories is calibrated jointly, allowing arbitrage-free restrictions across rating classes, as a bond migrates amongst them. We provide an illustration of the approach by applying it to price credit-sensitive notes that have coupon payments that are linked to the rating of the underlying credit.
\end{abstract}




\section{Pricing Credit Derivatives with Rating Transitions}

\section{Mini-Abstract}

The paper develops an arbitrage-free model jointly calibrating spread processes for all rating classes. 


\section{Introduction}

The pricing of credit derivatives is reaching a level of modeling maturity. In particular, "reduced form" models-models that attempt to directly describe the arbitrage-free evolution of risky debt values, without reference to an underlying firm value process-have resulted in successful conjoint implementations of term structure models with default models. ${ }^{1}$

Although all reduced-form models share a common financial-engineering approach, there are substantial differences in the modelling procedures actually followed. At least three branches of the literature may be identified.

First, there is the class of models that follow Duffie and Singleton [20] and Madan and Unal [36], [37] in taking as the starting point stochastic processes for the occurence of default and recovery. Implementation of the model is achieved by calibrating or estimating the parameters so that spreads implied by the model match those observed in the data.

Second, there is the approach of Das and Sundaram [11] and Schönbucher [42] in which an arbitragefree model is described directly for the joint evolution of riskless interest rates and spreads, taking as the only inputs the current term-structures of riskless interest rates and spreads and the volatilities of these quantities. This direct approach affords the advantage of simplicity in input requirements and flexibility in implementation. In particular, the model may be "closed" in a variety of ways, by superimposing on it any desired specification for the default process or the recovery rate process. ${ }^{2}$

Both approaches described above are models of risky debt pricing that are independent of references to bond ratings (i.e., it is as if there is a single ratings class). The third class of reduced form models explicitly uses ratings transition matrices as the drivers of the stochastic process for default (see, e.g. Arvantis, Gregory and Laurent [3], Bielecki and Rutkowski [4], Das and Tufano [12], Jarrow, Lando and Turnbull [26], Kijima [28], Kijima and Komoribayashi [29], and Lando [33]). ${ }^{3}$

In this paper, we present a discrete-time valuation model that merges the Das-Sundaram approach with a model with multiple ratings classes. As in Das and Sundaram, our model is based on the term-structure

\footnotetext{
${ }^{1}$ Reduced-form models are so-called in contrast to the class of "structural models" which build on the work of Merton [38]. Structural models start with a model of a firm value process, and value risky debt by either endogenizing default as a failure of the equityholders to meet the liabilities of the firm or assuming that default is triggered by firm value falling below a threshold barrier.

${ }^{2}$ The relation between the Duffie-Singleton approach and the Das-Sundaram approach is, in a sense, analogous to that between factor models of the term-structure (e.g., Vasicek [44]) and the Heath-Jarrow-Morton [24] approach. In particular, implementation of factor models requires assumptions about the model's risk-premium, or equivalently, about drifts in the risk-neutral world. In contrast, the HJM model takes the current term-structure of riskless rates and its volatilities as the sole inputs and describes an arbitrage-free evolution of the term-structure from this information alone.

${ }^{3}$ Other reduced-form models are presented in Duffee [15], Duffie and Huang [18], Duffie, et al [19], Jarrow and Turnbull [27], and Ramaswamy and Sundaresan [40].
} 
model of Heath, Jarrow, and Morton [24] (hereafter HJM), and extends the HJM model to include risky debt by adding a "forward spread" process to the forward rate process for default risk-free bonds. No restrictions are placed on the correlation between the processes, and the probability of default at any point in time is allowed to depend on the entire history of the process to that point. Our objective is to describe an arbitrage-free lattice for the joint evolution of riskless interest rates and spreads on the risky debt.

Das and Sundaram [11] describe the consruction of the required pricing lattice when there is only a single class of risky debt. This is sufficient for many applications, but becomes inappropriate for pricing credit derivatives and other instruments that are based explictly on an issuer's ratings class. ${ }^{4}$ In the current paper, we extend the Das-Sundaram framework to modeling the joint evolution of multiple-ratings classes on the same pricing lattice. The tricky part of this extension comes from a consistency requirement that arises when we attempt to embed all ratings categories on a single pricing lattice.

What is this consistency requirement? Since the credit quality or rating of a debt issuer can improve or deteriorate during the life of its debt, the current credit spread on its debt depends not only on the current rating of the issuer, but also on all possible ratings classes to which the issuer could migrate over the life of the debt. Thus, the current spread summarizes information about future credit spreads on all possible rating classes to which the borrower could migrate. This interdependence of spreads across rating classes implies that calibration of the spread process for a given rating class must be undertaken simultaneously with the calibration of the forward spread processes for all other rating classes. Formalizing this interdependence and characterizing the joint calibration process (Proposition 3.2) is a primary contribution of this paper.

One aspect of our modeling process bears mention. We do not directly model that movement of spreads of each rating class. Rather, we focus on the process for inter-rating spreads, i.e., the spread for that class over the immediately superior ratings class. (Of course, the spread over the default-free rate of any given ratings class is simply the sum of the inter-ratings spreads for that and all higher classes.) The advantage of working with inter-ratings spreads, rather than directly with spreads over default-free rates, is that, provided only that the inter-ratings spreads stay non-negative, spreads on lower-rated debt will always be higher than those on superior classes of debt. This restriction on the inter-rating spread processes is easier to model than a restriction that credit spreads for a given maturity be monotonically decreasing in credit quality. ${ }^{5}$

Finally, we note that our model requires only easily-available information as inputs. These are (i) the (default-)risk-free yield curve, (ii) the term structures of credit spreads for each rating class, (iii) the termstructures of volatilities of these quantities, and (iv) the (statistical) ratings transitions probability matrix. The first three pieces of information are readily available from such providers as Bloomberg, while the

\footnotetext{
${ }^{4}$ Such as, e.g., credit-sensitive notes, where the coupon size is tied to the issuer's credit rating.

${ }^{5} \mathrm{~A}$ model which is very close in spirit to that of ours in continuous time is developed by Bielecki and Rutkowski [4]. This model is also based on HJM and uses information about credit spreads coupled with that of transition probabilities and recovery rates to develop a conditionally Markovian model of credit risk. However, they model the evolution of spreads of each ratings class directly, and not via inter-rating spreads as we do.
} 
last-a standard input in all ratings-based models-may be computed from historical data, and is available from Moody's and Standard \& Poor.

The remainder of this paper is organized as follows. Section 2 describes the model and underlying assumptions. Section 3 describes the derivation of the recursive representation for the risk-neutral drifts, while Section 4 describes a recursive representation of risky bond prices in our model. Section 5 develops the implementation approach. Sections 6 and 7 consider an actual implementation example of a credit sensitive note that has coupon payments that are linked to corporate rating. Section 8 concludes.

\section{The Model}

The model is developed in discrete time, since a computer implementation for options with American features and path-dependence is envisaged. We consider an economy on a finite time interval $\left[0, T^{*}\right]$. Periods are taken to be of length $h>0$; thus, a typical time-point $t$ has the form $k h$ for some integer $k$. It is assumed that at all times $t$, a full range of default-free zero-coupon bonds trades, as does a full range of risky

zero-coupon bonds for each rating category. It is also assumed that markets are free of arbitrage, so there exists an equivalent martingale measure $Q$ for this economy; ${ }^{6}$ all references to randomness below and all expectations are with respect to this measure.

For any given pair of time-points $(t, T)$ with $0 \leq t \leq T \leq T^{*}-h$, let $f(t, T)$ denote the forward rate on the default-free bonds applicable to the period $(T, T+h)$; in words, $f(t, T)$ is the rate as viewed from time $t$ for a default-free lending/investment transaction over the interval $(T, T+h)$. All interest rates in the model are taken to be expressed in continuously-compounded terms. When $t=T$, the rate $f(t, t)$ is called the "short rate" and is denoted by $r(t)$. The forward rate curve is assumed to evolve according to the process

$$
f(t+h, T)=f(t, T)+\alpha(t, T) h+\sigma(t, T) X_{0} \sqrt{h},
$$

where $\alpha$ is the drift of the process and $\sigma$ its volatility; and $X_{0}$ is a random variable. Both $\alpha$ and $\sigma$ may depend on other information available at $t$, such as the time- $t$ forward rates. To keep notation simple, we have suppressed this possible dependence.

We assume there are $K+1$ rating classes, indexed by $k=1, \ldots, K+1$. Credit quality deteriorates from Class 1 down to Class $K+1$. Class $K+1$ is the "default state;" it is assumed that once a bond is in default state, it does not trade, and its price, net of any recovery upon default, is zero. For $0 \leq t \leq T \leq T^{*}-h$, let $\varphi(t, T)=\left[\varphi_{1}(t, T), \ldots, \varphi_{k}(t, T), \ldots, \varphi_{K}(t, T)\right]^{\prime}$ denote the "forward rates" on the risky bonds implied from

\footnotetext{
${ }^{6}$ Specifically, we assume that $Q$ is an equivalent martingale measure with respect to the money-market account $B(t)$ defined in (3.1) below. See Harrison and Kreps [22] or Harrison and Pliska [23] for the role of equivalent martingale measures in securities modeling.
} 
the spot yield curve. The forward inter-rating spreads are defined as the spreads between successive rating categories. These comprise a vector:

$$
\mathbf{s}(t, T)=\left[s_{1}(t, T), \ldots, s_{k}(t, T), \ldots, s_{K}(t, T)\right]^{\prime}
$$

where $s_{1}=\varphi_{1}-f, s_{2}=\varphi_{2}-\varphi_{1}$, etc. Note, of course, that the forward spreads on risky debt are related to the inter-rating spreads as

$$
\varphi_{k}(t, T)=f(t, T)+s_{1}(t, T)+\ldots+s_{k}(t, T), \quad \forall k .
$$

As long as $s_{k}(t, T)>0$ for all $k$, we are assured that credit spreads are increasing as the quality level decreases.

Next, we make assumptions concerning the evolution of the forward inter-rating spreads (and, thus, of the forward rates on the risky bonds). We take these to follow the process

$$
s_{k}(t+h, T)=s_{k}(t, T)+\beta_{k}(t, T) h+\eta_{k}(t, T)^{\prime} \mathbf{X} \sqrt{h}, \quad \forall k,
$$

where $\beta_{k} \in \mathbb{R}$ and $\eta_{k} \in \mathbb{R}^{L}$ are the drift and volatility coefficients of the process, respectively, and $\mathbf{X} \in \mathbb{R}^{L}$ are (possibly correlated) random variables. Define

$$
\begin{aligned}
\beta(t, T) & =\left[\beta_{1}(t, T), \ldots, \beta_{k}(t, T), \ldots, \beta_{K}(t, T)\right]^{\prime} \in \mathbb{R}^{K} \\
\eta(t, T) & =\left[\eta_{1}(t, T), \ldots, \eta_{k}(t, T), \ldots, \eta_{K}(t, T)\right] \in \mathbb{R}^{L \times K}
\end{aligned}
$$

Note that $L$, the dimension of the space of diffusion factors that affect the spread processes, can, in general, be smaller than, greater than, or equal to $K$. Both $\beta$ and $\eta$ may depend on other information available at $t$. At this point, we place no restrictions on the joint distribution of $X_{0}$ and $\mathbf{X}$. When illustrating implementation of the model in a later section, we will assume that the random variables $\left(X_{0}, \mathbf{X}\right)$ take values on a discrete state-space.

We will denote by $P(t, T)$ the time- $t$ price of a default-free zero-coupon bond of maturity $T \geq t$, and by $\Pi_{k}(t, T)$ its risky counterpart in the $k^{\text {th }}$ rating class. Note that, by definition, we have

$$
\begin{aligned}
& P(t, T)=\exp \left\{-\sum_{i=t / h}^{T / h-1} f(t, i h) \cdot h\right\} \\
& \Pi_{k}(t, T)=\exp \left\{-\sum_{i=t / h}^{T / h-1} \varphi_{k}(t, i h) \cdot h\right\}, \quad \forall k
\end{aligned}
$$


Default is modeled using a Markov chain that governs the transitions of each bond from one rating level $k$ to another, in a time period of length $h$. We denote this Markov chain as:

$$
D=\left[\begin{array}{cccc}
q_{1,1} & \ldots & \ldots & q_{1, K+1} \\
: & & & : \\
q_{K, 1} & & & q_{K, K+1} \\
q_{K+1,1} & \ldots & \ldots & q_{K+1, K+1}
\end{array}\right]
$$

Since we have taken default to be an absorbing state, we can write

$$
D=\left[\begin{array}{cccc}
q_{11} & \ldots & \ldots & q_{1, K+1} \\
: & & & : \\
q_{K, 1} & & & q_{K, K+1} \\
0 & 0 & \ldots & 1
\end{array}\right]
$$

The elements of $D$ depend, of course, on the size of the time step $h$. Moreover, they could be functions of the information set as well as time. To reduce the notational burden, we suppress this dependence. The idea of using ratings-transition matrices as a modeling input was first explored in Jarrow, Lando and Turnbull [26]. As in Jarrow, Lando and Turnbull [26], we assume that the rating transition process is independent of the stochastic processes driving the evolution of the model's forward rates.

The spreads on the risky bonds represent the cost of default, and as such, depend on both the probability of default (which depends, in turn, on the sequence of rating transitions till maturity of the bond) as well as the amount that bond holders expect to recover in the event of default. Given that default has not occurred up to $t$, we denote by $\lambda_{k}(t) \equiv q_{k, K+1}(t)$, the probability of default by time $t+h$ from state $k$. Concerning recovery in the event of default, we will use the "Recovery of Market Value" or RMV convention of Duffie and Singleton [20] that expresses the recovery rate as a fraction of the market value that would have prevailed in the absence of default. Specifically, let $\Phi^{t}$ denote the actual recovery amount in the event of default at $t$. The RMV convention then states that conditional on default occurring at time $t+h$, the time- $t$ expectation $E^{t}\left[\Phi^{t+h}\right]$ of the amount bondholders will receive is

$$
E^{t}\left[\Phi^{t+h}\right]=\phi_{k}(t) E^{t}[\Pi(t+h, T) \mid \text { No Default }]
$$

where the recovery rate $\phi_{k}(t)$ depends on the state $k$ from which default occurred. Recovery rates may be chosen so as to be different depending on the rating class from which the bond has moved to the default state. As with $\lambda, \phi_{k}(t)$ may also depend on all information in the model up to and including period $t$. It may also depend on the subordination level of the bond. The recovery rate may not be specific to the initial rating class, since eventually all defaulting bonds are in the default category. 
The following preliminary result relating short spreads to the default probabilities and recovery rates under $Q$ will come in handy in the rest of the paper:

$$
\sum_{j=1}^{k} s_{j}(t, t)=-\frac{1}{h} \ln \left[1-\lambda_{k}(t)+\lambda_{k}(t) \phi_{k}(t)\right], \quad \forall k .
$$

To see (2.7), consider a risky bond at $t$ that matures at $(t+h)$. By definition, its time- $t$ price is given by

$$
\Pi_{k}(t, t+h)=\exp \left\{-\left(f(t, t)+\sum_{j=1}^{k} s_{j}(t, t)\right) \cdot h\right\}, \quad \forall k .
$$

Now, a one period investment in this bond fetches a cash flow of $\$ 1$ at time $(t+h)$ if there is no default at $t+h$, and a cash flow of $\phi_{k}(t)$ if there is a default. When discounted at the short rate, the expected cash flow (in the risk-neutral world) must equal the initial price of the bond, so we obtain

$$
\Pi_{k}(t, t+h)=\exp \{-f(t, t) h\}\left[1-\lambda_{k}(t)+\lambda_{k}(t) \phi_{k}(t)\right], \quad \forall k .
$$

Expression (2.7) is an immediate consequence of (2.8) and (2.9).

The model's objective is to develop a risk-neutral lattice for pricing risky debt. This is undertaken in several steps. First, the lattice of default-free interest rates is generated by solving for the risk-neutral drifts so that all discounted default-free securities are martingales. Then, a lattice for credit spreads is superimposed on the first lattice, and risk-neutral drifts are computed for the forward spread process so that the discounted prices of risky debt are martingales. Finally, the recursive structure of the model is used together with a specific assumption concerning the default process to illustrate implementation of the model. We begin with identification of the risk-neutral drifts.

\section{Identifying the Risk-Neutral Drifts}

In this section, we derive recursive expressions for the drifts $\alpha$ and $\beta$ of the forward-rate and spread processes, respectively, in terms of the volatilities $\sigma$ and $\eta$. To this end, we define $B(t)$ to be the time- $t$ value of a "money-market account" that uses an initial investment of $\$ 1$, and rolls the proceeds over at the default-free short rate:

$$
B(t)=\exp \left\{\sum_{i=0}^{t / h-1} r(i h) \cdot h\right\} .
$$

We assume, without loss of generality, that the equivalent martingale measure $Q$ was defined with respect to $B(t)$ as numeraire; thus, under $Q$ all asset prices in the economy discounted by $B(t)$ will be martingales. 
We first identify the risk-neutral drifts $\alpha$ of the default-free forward rates under $Q$. A well-known property of the HJM framework is that these risk-neutral drifts can be expressed entirely in terms of the forward-rate volatilities $\sigma$. To be precise:

Proposition 3.1 (Drift of the Default-Free Forward Rate Process) For any $t$, the following recursive relationship holds between the drifts $\alpha$ and the volatilities $\sigma$ :

$$
\sum_{i=t / h+1}^{T / h-1} \alpha(t, i h)=\frac{1}{h^{2}} \ln \left(E^{t}\left[\exp \left\{-\sum_{i=t / h+1}^{T / h-1} \sigma(t, i h) X_{0} h^{3 / 2}\right\}\right]\right) .
$$

Proof See Appendix A.

The next step is to obtain an analog of Proposition 3.1 for the drifts $\beta(t, T)$ of the forward inter-rating spread processes in terms of their volatilities. This representation is, however, a bit trickier than for defaultfree rates. A risky bond with a current rating of $k$ may move to a different rating class tomorrow. As such, the current price of the bond (equivalently, the spread for its rating class) implicitly carries information about future spreads associated with other rating classes also. This implies, in turn, the presence of simultaneous no-arbitrage restrictions on how the drifts of different classes evolve with respect to each other. The following result unravels this dependence and shows how the relevant drifts may be calculated in a bootstrapping manner:

Proposition 3.2 (Drifts of the Forward Inter-Rating Spread Processes) For $j=1, \ldots, K$, let $\theta_{j}$ be defined by $\theta_{j}(t, i h)=\sum_{l=1}^{j} \beta_{l}(t, i h)$. Then, at each $t$, the vector $\left[\theta_{1}(t, i h), \ldots, \theta_{K}(t, i h)\right]$ must solve the following system of $K$ equations in $K$ unknowns $\left(x_{j}, j=1, \ldots, K\right)$ :

$$
\sum_{j=1}^{K} a_{k, j} \cdot b_{k, j} \cdot x_{j}=1, \quad k=1, \ldots, K
$$

where

$$
\begin{aligned}
& a_{k, j}=\frac{q_{k, j}(t)}{1-\lambda_{k}(t)} \cdot \exp \left\{-\sum_{i=\frac{t}{h}+1}^{\frac{T}{h}-1} \alpha(t, i h) \cdot h^{2}\right\} \cdot \exp \left\{-\sum_{i=\frac{t}{h}+1}^{\frac{T}{h}-1}\left(\varphi_{j}(t, i h)-\varphi_{k}(t, i h)\right) \cdot h\right\} \\
& b_{k, j}=E^{t}\left[\exp \left\{-\sum_{i=\frac{t}{h}+1}^{\frac{T}{h}-1}\left(\sigma(t, i h) X_{0}+\sum_{l=1}^{j} \eta_{l}(t, i h)^{\prime} \mathbf{X}\right) \cdot h^{\frac{3}{2}}\right\}\right], \text { and } \\
& x_{j}=\exp \left\{-\sum_{i=\frac{t}{h}+1}^{\frac{T}{h}-1} \theta_{j}(t, i h) \cdot h^{2}\right\} .
\end{aligned}
$$




\section{Proof See Appendix A.}

These expressions are much less forbidding than they may first appear. The system is linear in the $x_{j}$ variables. At each state at time $t$ in rating class $k$, the terms $a_{k, j}$ can be computed knowing the transition probabilities, the $\alpha$ drift terms, and the spread levels at that state. Similarly, the terms $b_{k, j}$ can be computed by taking the expectation over the diffusion processes $\left(X_{0}, \mathbf{X}\right)$, as is illustrated in pseudo code later, knowing the term structure of forward interest rate volatilities and forward inter-rating spread volatilities. Thus, solving the above system of linear equations (using standard algorithms such as GaussSeidel for example), we obtain the $x_{j}$ terms, which in turn yield $\theta_{j}$ terms. Since the system is to be solved in a bootstrap manner starting with $T-1$, the drift terms $\beta_{j}(t, \cdot)$ can then be backed out from the knowledge of $\theta_{j}(\cdot, \cdot)$.

The presence of multiple ratings classes prevents this representation from providing an analytical expression for drift terms $\beta(t, T)$, as is obtained in the single-rating model of Das and Sundaram [11]. However, the expectation in relation (3.5) over all possible sample-paths of the state-space for $X_{0}$ and $\mathbf{X}$ can be computed numerically using a lattice as we illustrate in this paper. This completes the derivation of the risk-neutral drifts in terms of the volatilities.

\section{A Recursive Representation of the Risky Bond Prices}

The prices of a risky bond in our model, as in Das and Sundaram [11], have a recursive representation, which leads, in turn, to a representation in terms of bond prices of short maturities, i.e. of the form $\Pi_{k}(\tau, \tau+h)$. We describe this representation here. While in Das and Sundaram, the recursive representation entails one level of recursion at each time step, with possible rating transitions, our representation forks into $K$ levels of recursion at each time step.

It is straightforward to show (see Expression (A.10) in Appendix A) that

$$
\exp \left\{-\varphi_{k}(t, t) \cdot h\right\} \cdot E_{k}^{t}[\Pi(t+h, T) \mid \text { No Default }]=\Pi_{k}(t, T) .
$$

Rearranging terms and using the fact that $\exp \left\{-\varphi_{k}(t, t) \cdot h\right\}=\Pi_{k}(t, t+h)$, we now obtain

$$
\begin{aligned}
\Pi_{k}(t, T) & =\Pi_{k}(t, t+h) \cdot E_{k}^{t}[\Pi(t+h, T) \mid \text { No Default }] \\
& =\Pi_{k}(t, t+h) \cdot \sum_{j=1}^{K} \frac{q_{k, j}(t)}{1-\lambda_{k}(t)} E^{t}\left[\Pi_{j}(t+h, T)\right]
\end{aligned}
$$

We can now iterate on the expression for $\Pi_{j}(t+h, T)$ in terms of the transition probabilities $q_{j, l}(t+h)$ and $E^{t+h}\left[\Pi_{l}(t+h, T) \mid\right.$ No Default $], l=1, \ldots, K$. 
The recursive structure of the prices of risky bonds as described in (4.3) facilitates computation of these prices. Note that since all terms on the right hand side have the form $F(\tau, \tau+h)$, we can make use of relation (2.9) to employ the forward spread components (i.e., the default and recovery rates) in this process.

\section{Implementation of the Model}

To be able to implement the model, we must be more precise about quantities that have so far been left unspecified, viz., the random variables $X_{0}$ and $\mathbf{X}$. In this section, we describe the assumptions that we will use in the rest of this paper. These assumptions were chosen with an eye towards simplicity both in exposition and in implementation, but they are primarily meant to be illustrative; alternative assumptions may, of course, be similarly handled.

We first assume that $K=2$, so that the three possible states of the corporate bond are Investment Grade $(k=1)$, Speculative Grade $(k=2)$, and Default State $(k=3)$. We make the discrete-time assumption that $X_{0}$ and $\mathbf{X}$, i.e. $X_{0}, X_{1}$, and $X_{2}$ are binomial random variables, specifically, that each takes on the values \pm 1 with probability $1 / 2$. We assume that the pairwise correlation between $X_{0}$ and $X_{1}$ is $\rho_{1}$, between $X_{0}$ and $X_{2}$ is $\rho_{2}$ and between $X_{1}$ and $X_{2}$ is $\rho_{3}$. So, the assumed joint distribution of $\left(X_{0}, X_{1}, X_{2}\right)$ is

$$
\left(X_{0}, X_{1}, X_{2}\right)= \begin{cases}(+1,+1,+1), & \text { w.p. } q_{u u u}=\left(1+\rho_{1}+\rho_{2}+\rho_{3}\right) / 8 \\ (+1,+1,-1), & \text { w.p. } q_{u u d}=\left(1+\rho_{1}-\rho_{2}-\rho_{3}\right) / 8 \\ (+1,-1,+1), & \text { w.p. } q_{u d u}=\left(1-\rho_{1}+\rho_{2}-\rho_{3}\right) / 8 \\ (+1,-1,-1), & \text { w.p. } q_{u d d}=\left(1-\rho_{1}-\rho_{2}+\rho_{3}\right) / 8 \\ (-1,+1,+1), & \text { w.p. } q_{d u u}=\left(1-\rho_{1}-\rho_{2}+\rho_{3}\right) / 8 \\ (-1,+1,-1), & \text { w.p. } q_{d u d}=\left(1-\rho_{1}+\rho_{2}-\rho_{3}\right) / 8 \\ (-1,-1,+1), & \text { w.p. } q_{d d u}=\left(1+\rho_{1}-\rho_{2}-\rho_{3}\right) / 8 \\ (-1,-1,-1), & \text { w.p. } q_{d d d}=\left(1+\rho_{1}+\rho_{2}+\rho_{3}\right) / 8\end{cases}
$$

We note that, in general, the correlation coefficients may not be equal to zero or even constant over the tree. For some numerical estimates of the correlation coefficient between corporate spreads and interest rates in general, see Das and Sundaram [11], and Das and Tufano [12].

Next, we look at the components of the forward rates, namely the default rate $\lambda_{k}(t)$, and the recovery rate $\phi_{k}(t)$. Using equation (2.7), it is clear that knowing the forward spreads $s_{k}(t, t)$ and either of $\lambda_{k}(t)$ or $\phi_{k}(t, t)$ for all $k$, implies the other. Unlike Das and Sundaram [11], where an additional specification is required linking the default rate $\lambda(t)$ to the interest rate and the spread variables, in our model, $\lambda_{k}(t)$ 's are to be used based on the rating transition matrix. In particular, $\lambda_{k}(t) \equiv q_{k, K+1}(t)$.

One last, and non-trivial, issue remains before we can discuss the engineering details of model implementation. Estimates of the probabilities provided in standard rating transition matrices (e.g. of Moody's 
and Standard and Poor's) based on historical data cannot be directly used in our model, since our model (including the probability of default $\lambda_{k}(t)$ ) is set in the risk-neutral world. Thus, a translation from the actual to the risk-neutral measure is required. To this end, suppose that $\lambda_{k}^{P}(t)$ denotes the actual probability of default. We will make the natural assumption that the recovery rates are the same in the risk-neutral and actual worlds, so realized cash flows coincide in the two cases. Letting $\xi_{k}(t)$ be the time- $t$ premium for bearing default risk corresponding to rating state $k$, the analog of (2.7) under the actual probabilities is easily derived:

$$
\exp \left\{-s_{k}(t, t) h\right\}=\exp \left\{-\xi_{k}(t) h\right\}\left[1-\lambda_{k}^{P}(t)+\phi_{k}(t) \lambda_{k}^{P}(t)\right]
$$

The difference between (2.7) and (5.2) is simply that the relationship (2.7) is developed in the risk-neutral world, where-by definition-there is no premium for bearing risk. Expression (5.2) follows the same derivation but is set in the actual world, where we would expect that the risk-premium term $\xi_{k}(t)$ would be positive.

Comparing (2.7) and (5.2), we may express $\lambda_{k}(t)$ in terms of $\lambda_{k}^{P}(t)$ and the risk-premium $\xi_{k}(t)$ :

$$
\lambda_{k}(t)=\lambda_{k}^{P}(t)\left[\frac{1-\exp \left\{-s_{k}(t, t) h\right\}}{1-\exp \left\{-\left(s_{k}(t, t)-\xi_{k}(t)\right) h\right\}}\right] .
$$

Expression (5.3) implies the intuitive condition that $\lambda_{k}>\lambda_{k}^{P}$ whenever the risk-premium $\xi_{k}$ is positive.

These expressions may be used in conjunction with equation (2.7) to estimate the risk-premium terms $\xi_{k}(t)$. Specifically, we get

$$
\phi_{k}(t)=\frac{1}{\lambda_{k}^{P}(t)}\left[\exp \left\{-\left(s_{k}(t, t)-\xi_{k}(t)\right) h\right\}-1+\lambda_{k}^{P}(t)\right] .
$$

In estimation, we can use $\phi_{k}(t)$ to be the average recovery rate observed historically for the rating class $k, \bar{\phi}_{k}(t)$. Thus, knowing the actual recovery rate $\bar{\phi}_{k}(t)$, the actual default rate $\lambda_{k}^{P}(t)$ and the actual spot spread $s_{k}(t, t)$, the risk-premium terms $\xi_{k}(t)$ can be backed out using equation (5.4). Or, as in Das and Sundaram [11], we can assume that the risk-premium terms are given by $\xi_{k}(t, t)=\nu_{k} s_{k}(t, t)$ for scalar $\nu_{k}$, and use equation (5.4) to back out implied recovery rate functions $\phi_{k}(t)$.

An additional complication remains, which is to adjust the remaining elements of the historical transition matrix to obtain the risk-neutral transition matrix. We make an assumption similar to that in Jarrow, Lando and Turnbull [26], and assume that

$$
\begin{aligned}
q_{k, l}(t) & =\delta_{k}(t) \cdot q_{k, l}^{P}(t), \forall l \neq k \\
q_{k, k}(t) & =1+\delta_{k}(t) \cdot\left[q_{k, k}^{P}(t)-1\right], \text { where } \\
\delta_{k}(t) & =\frac{\lambda_{k}(t)}{\lambda_{k}^{P}(t)} .
\end{aligned}
$$


Note that $q_{k, l}(t)$ refers to transition probabilities in the risk-neutral matrix whereas $q_{k, l}^{P}(t)$ refers to transition probabilities in the historical matrix. Also, $q_{k, K+1}^{P}(t)=\lambda_{k}^{P}(t)$ so that $q_{k, K+1}(t)=\lambda_{k}(t)$.

Such a "spread" transformation, where the mass spreads from the diagonal term of the transition matrix to the off-diagonal terms, has also been employed by Wilson [45]. Note that more sophisticated techniques for estimation of $\delta_{k}(t)$ would try to minimize error over the entire transition matrix data rather than just the default transition probability, $\lambda_{k}(t)$, as we did in the possible estimation techniques described in the previous paragraph.

\section{Lattice Implementation}

We describe in this section an implementation of our model using a lattice. The lattice has a multidimensional structure, since it combines the evolution of interest rates and inter-rating spreads for different rating classes. At the same time, the rating transition process is superimposed on top of this lattice. This superimposition is straightforward since we have assumed that the rating transition process is independent of the diffusion processes.

First, let us look only at the multidimensional structure for the interest rate and the spread processes. We assume as before that there are only three possible rating classes: Investment Grade (denoted as I), Speculative or Junk Grade (denoted as $J$ ), and Default State (denoted as $D$ ). Thus $K=2$, and we have two inter-rating spread processes $s_{I}$ and $s_{J}$. Thus, along with the interest rate process, we obtain a triple-binomial structure with eight branches emanating from each node of the lattice. This part of the lattice looks similar to that in Das and Sundaram ([11]). Specifically, once the risk-neutral drifts $\alpha(\cdot), \beta(\cdot)$ have been computed at any $t$, the possible values of the forward rates and forward spreads one period out are readily obtained using (2.1) and (2.3).

At each state, the current rating class is known as well. Thus, if further given the forward and spread curves $F(\tau)=(f(\tau, \cdot)), S_{I}(\tau)=\left(s_{I}(\tau, \cdot)\right)$, and $S_{J}(\tau)=\left(s_{J}(\tau, \cdot)\right)$ at any $\tau$, and knowing the one-period default probability $\lambda(\tau)$ as the default probability in one-period for the current rating class, the recovery rate $\phi(\tau)$ can be computed as described in the previous section.

So far, at each node on the lattice we have information related to all three risks involved in the valuation of risky debt (interest rates, default probabilities, and recovery rates). However, in order to obtain the possible one-period ahead values of risky debt, we need to superimpose the rating transition process on the lattice. We describe this the next.

From each of the eight nodes of the triple-binomial spread lattice, three rating transitions emanate. Thus, if the current rating class at the source node was $k$, then three transitions $k \rightarrow I, k \rightarrow J$, and $k \rightarrow D$ are possible, with probabilities $q_{k, I}, q_{k, J}$, and $q_{k, D}$ respectively. From each of the sixteen non-default states 
so obtained (note that the default state $D$ is an absorbing state), another superimposition of triple-binomial lattice and rating transition matrix evolves.

Thus, at each node, we carry the information set $\left(F, S_{I}, S_{J}, \lambda_{k}, \phi_{k}\right)$ where $k$ is the current rating. As in Das and Sundaram ([11]), we also carry at each node the state-price of the node and cumulative default probability till the node. This provides all the information that is necessary to price a wide range of standard credit instruments and derivatives.

Figure 1 illustrates the rating migration process superimposed on the triple-binomial lattice at one of the nodes. The up and down states for the interest rate process, $F_{u}$ and $F_{d}$, correspond to $X_{0}=+1$ and $X_{0}=-1$, respectively, with similar notation used for $S_{I}$ and $S_{J}$ as well.

The code for calibrating the tree is described in Appendix B. For simplicity, we have assumed in the code that $\sigma(t, T), \eta_{I}(t, T)$, and $\eta_{J}(t, T)$, depend only on $\mathrm{T}$. Also, as assumed all through the text, the correlation coefficients between $X_{0}, X_{1}, X_{2}$ and the rating transition matrix $D$ are assumed constant. To consider a numerical example, we consider the calibration exercise for a tree of three periods with the following parameter specifications. $X_{1}$ and $X_{2}$ are assumed to be perfectly correlated $\left(\rho_{3}=1\right)$. The correlations between $X_{0}$ and $X_{1}$, and between $X_{0}$ and $X_{2}$, are assumed to be identical, $\rho_{1}=\rho_{2}=0.25$. The time-step in the tree is $h=0.5$ (half a year). The initial values for forward risk-free rate and inter-rating spreads, and the volatility terms of forward risk-free rate and inter-rating spread processes, are as described in the table below:

\begin{tabular}{|c|c|c|c|c|c|c|}
\hline$i$ & $f(t, t+i h)$ & $s_{I}(t, t+i h)$ & $s_{J}(t, t+i h)$ & $\sigma(t, t+i h)$ & $\eta_{I}(t, t+i h)$ & $\eta_{J}(t, t+i h)$ \\
\hline 1 & 0.06 & 0.02 & 0.04 & 0.010 & 0.005 & 0.005 \\
2 & 0.07 & 0.02 & 0.04 & 0.011 & 0.006 & 0.006 \\
3 & 0.08 & 0.03 & 0.05 & 0.012 & 0.006 & 0.007 \\
\hline
\end{tabular}

The rating transition process under the risk-neutral measure is taken to be:

$$
D=\left[\begin{array}{ccc}
0.70 & 0.20 & 0.10 \\
0.10 & 0.75 & 0.15 \\
0 & 0 & 1
\end{array}\right]
$$

Under this parameter specification, the tree for the evolution of the risk-free forward rate and the interrating forward spreads is shown in Table 1 . Note that unlike Figure 1, the rating transitions are not shown as superimposed in this tree even though the probabilities of these transitions are required for accurate no-arbitrage calibration of the risk-neutral drifts (Proposition 3.2).

In addition, the number of branches is reduced since the two inter-rating spread processes are assumed to be perfectly correlated. Thus at first period, there are four nodes possible, viz. $u u, u d, d u$, and $d d$, with probabilities, $\frac{1}{4}(1+\rho), \frac{1}{4}(1-\rho), \frac{1}{4}(1-\rho)$, and $\frac{1}{4}(1+\rho)$, i.e., $0.3125,0.1875,0.1875$, and 0.3125 , 
respectively. From each of these nodes, four nodes emanate again.

At each node in the tree at time $i h$ (initial node being $i=0$ ), the three columns indicate the forward riskfree rate, the forward inter-rating spread between risk-free and investment grade rating $(I)$, and the forward inter-rating spread between investment grade rating $(I)$ and speculative grade rating $(J)$, respectively, for maturities $(i+1) h, \ldots, T=1.5$ years. Using these forward rates, the tree for zero bond prices for risk-free bond, investment grade bond, and speculative grade bond, can be readily constructed using equations (2.4) and (2.5). This tree is shown in Table 2. The zero bond prices constitute the fundamental prices using which other instruments can be priced.

We next illustrate this by pricing a credit-related instrument in our framework, taking the example of Credit Sensitive Note, whose valuation requires modeling both default risk as well as rating migrations. Other instruments can be priced analogously.

\section{Example: Credit Sensitive Note}

A Credit Sensitive Note (CSN) is a corporate coupon bond whose coupon is linked to the rating of the corporate. For example, in June 1989, Enron Corp. issued $\$ 100 \mathrm{ml}$. in non-callable 9.5\% Credit Sensitive Notes, to mature on June 15, 2001. The coupon on these notes was linked to Enron's credit rating, as measured by either Standard \& Poor's or Moody's. The coupon on the notes was structured such that, when Enron's credit rating changed (at the time of issuance, its outstanding senior debt had ratings BBBand $\mathrm{Baa} 3$, respectively under the two rating agencies), the coupon rate changed as well. To be specific, the coupon rate was set to drop incrementally for improvements in Enron's ratings, and it would climb steeply if the rating deteriorated. The exact schedule of coupon is tabulated below. ${ }^{7}$

\footnotetext{
${ }^{7} \mathrm{~A}$ more recent example of a CSN comes from an issue by Olivetti, which announced on June 7th, 2000, that it plans to link the coupon on 18 billion euros ( $\$ 17$ billion) of bonds sold by itself and its Tecnost SpA unit to their credit rating. Investors will be paid off if the rating worsens, less if the grade recovers. As stated by Olivetti's chief financial officer, Luciano La Noce - "The coupon adjustment will be applicable to all of the outstanding issues. Going forward, we think having these sort of volatility protection measures associated with our bonds should result in a lower capital cost." (source: Bloomberg).
} 


\begin{tabular}{|c|c|c|}
\hline Moody's Rating & S\&P rating & Coupon Rate \\
\hline Aaa & AAA & $9.20 \%$ \\
Aa1-Aa3 & AA+ - AA- & $9.30 \%$ \\
A1-A3 & A+ - A- & $9.40 \%$ \\
Baa1-Baa3 & BBB+ - BBB- & $9.50 \%$ \\
Ba1 & BB+ & $12.00 \%$ \\
Ba2 & BB & $12.50 \%$ \\
Ba3 & BB- & $13.00 \%$ \\
B1 or lower & B+ or lower & $14.00 \%$ \\
\hline
\end{tabular}

In our setup, we will assume that the coupon amount on a coupon payment date is linked to the corporate rating prevailing at the previous coupon payment date. In our three rating classes model, the CSN has a coupon of $c_{I}$ for investment grade rating and $c_{J}$ for junk grade rating. Such a note cannot be priced using a pure spread-based model of credit or a pure intensity-based model of credit. The model described in this paper, however, lends itself appropriately to the valuation of a CSN.

The valuation of CSN along the lattice in our model is straightforward. At each node of the lattice, the current rating class is available in the information set at the node. This determines the coupon payment scheduled for next coupon payment date. The "up-grading" and "down-grading" along the lattice produce the resetting of the coupon during the life of the schedule, as per the coupon vs. rating schedule. Thus, discounting the cashflows in default and non-default states, and moving backwards along the tree yields the price of the CSN.

To be more precise, using the recursive implementation discussed in Section 4, the price of the credit sensitive note, $C S N_{k}(t, T)$, is given as:

$$
C S N_{k}(t, T)=\Pi_{k}(t, t+h) \cdot\left[c_{k}+\sum_{j=1}^{K} \frac{q_{k, j}(t)}{1-\lambda_{k}(t)} \cdot E^{t}\left[C S N_{j}(t+h, T)\right]\right] .
$$

Note that $\Pi_{k}(t, t+h)$ is already available from the zero bond price tree, $c_{k}$ represents the coupon next period which is "set" today given the current rating ' $k$ ', and the second term inside [ · ] represents the value of the credit sensitive note at the nodes tomorrow after possible rating migrations. The code for this procedure is described in Appendix B.

As an illustration, we consider a variant of the Enron CSN that has 1.5 years to maturity (three period note with $h=0.5$ year). The coupons for different ratings are: $c_{I}=0.04675$, and $c_{J}=0.06375$, which correspond to semi-annual coupons of $9.35 \%$ and $12.75 \%$, respectively. Using the recursive scheme described above (or simply by reducing the scheme to a backwards induction procedure), the CSN can be priced off the zero bond price tree. The tree for CSN prices is described in Table 3. At each node, the two columns 
represent the CSN price for investment grade and speculative grade ratings, respectively. For example, at $t=0$, the CSN price is 0.994146 if the underlying credit has investment grade rating, but the price would be lower at 0.984822 if the underlying credit had speculative grade rating.

At $t=1.0$ year, the price of the note is easy to determine since its coupon payment is "set" for maturity at $T=1.5$ years. The price is thus simply equal to

$$
\left(1.0+c_{k}\right) \cdot \Pi_{k}(t, t+h)
$$

where $k$ is the current rating of the underlying credit. Consider now the state of the world $u u$ at $t=0.5$ year when the underlying credit has speculative grade rating. Its price can be computed using equation (7.1) as:

$$
\begin{aligned}
& C S N_{J}(t=0.5, T=1.5)=0.93169 \cdot[0.06375+ \\
& \frac{0.10}{0.85} \cdot[(0.3125)(0.980370)+(0.1875)(0.986270)+(0.1875)(0.986270)+(0.3125)(0.992206)]+ \\
& \frac{0.70}{0.85} \cdot[(0.3125)(0.968530)+(0.1875)(0.977286)+(0.1875)(0.974359)+(0.3125)(0.983168)] \\
& \quad]=0.969719 .
\end{aligned}
$$

To see how the credit sensitivity of the coupon payments plays a role in the pricing of the CSN, Table 4 shows the tree for prices for a credit insensitive note that has a fixed coupon of 0.04675 , irrespective of the rating of the underlying credit. Consider the price of this note at $t=0$ with investment grade rating. It is 0.985483 , whereas that of the otherwise identical CSN is 0.994146 . The difference in value comes from two parts: (i) At all nodes at $t=0.5$ year, if the rating were to "fall" to speculative grade, the CSN would have an upward jump in coupon payment from 0.04675 to 0.06375 . (ii) At all nodes at $t=0.5$ year, even if the rating were to "stay" as investment grade, the price of the CSN would be higher due to the increase in future coupon payments whenever there is a downgrading. Both these effects are observed by comparing $t=0.5$ year prices across the trees for credit sensitive note (Table 3 ) and credit insensitive note (Table 4).

Instruments other than credit sensitive notes that have embedded optionality that is tied to credit quality of the underlying can be priced analogously in a relatively simple manner using our approach.

\section{Concluding Comments}

This paper develops a model for the pricing of credit derivatives using observables. The model is (i) arbitrage-free, (ii) accommodates path-dependence, (iii) allows for all rating classes in one consistent lattice framework, and (iv) can handle a range of securities that have a credit related component. The computer 
implementation uses a recursive scheme that is convenient and seamlessly processes forward induction and backward recursion, needed to compute more complicated derivative securities. While the model is rich and flexible enough to price any credit-related instrument, it is particularly appropriate for pricing credit sensitive notes that have payments linked to rating transitions.

\section{A Proofs}

Proof of Proposition 3.1: Let $Z(t, T)$ denote the price of the default-free bond discounted using $B(t)$ :

$$
Z(t, T)=\frac{P(t, T)}{B(t)}
$$

Since $Z$ is a martingale under $Q$, for any $t<T$ we must have $Z(t, T)=E^{t}[Z(t+h, T)]$, or, equivalently,

$$
E^{t}\left[\frac{Z(t+h, T)}{Z(t, T)}\right]=1
$$

Now, $Z(t+h, T) / Z(t, T)=(P(t+h, T) / P(t, T)) \cdot(B(t) / B(t+h))$. Using (2.4), some algebra reveals the first term to be

$$
\frac{P(t+h, T)}{P(t, T)}=\exp \left\{-\left(\sum_{i=t / h+1}^{T / h-1}[f(t+h, i h)-f(t, i h)] \cdot h\right)+f(t, t) h\right\} .
$$

The second term $B(t) / B(t+h)$ is evidently just $\exp \{-f(t, t) h\}$. Combining these, we obtain

$$
\frac{Z(t+h, T)}{Z(t, T)}=\exp \left\{-\sum_{i=t / h+1}^{T / h-1}[f(t+h, i h)-f(t, i h)] \cdot h\right\},
$$

Using (A.4) in (A.2), the martingale condition becomes

$$
E^{t}\left[\exp \left\{-\sum_{i=t / h+1}^{T / h-1}[f(t+h, i h)-f(t, i h)] \cdot h\right\}\right]=1 .
$$

Substituting for $(f(t+h, i h)-f(t, i h))$ from (2.1), this is the same as

$$
E^{t}\left[\exp \left\{-\sum_{i=t / h+1}^{T / h-1}\left[\alpha(t, i h) h^{2}+\sigma(t, i h) X_{0} h^{3 / 2}\right]\right\}\right]=1 \text {. }
$$


Since $\alpha(t, \cdot)$ is known at $t$, it may be pulled out of the expectation. This gives us after some rearranging the promised recursive expression relating the risk-neutral drifts $\alpha$ to the volatilities $\sigma$ at each $t$ :

$$
\sum_{i=t / h+1}^{T / h-1} \alpha(t, i h)=\frac{1}{h^{2}} \ln \left(E^{t}\left[\exp \left\{-\sum_{i=t / h+1}^{T / h-1} \sigma(t, i h) X_{0} h^{3 / 2}\right\}\right]\right) .
$$

Proof of Proposition 3.2: Pick any $t<T$ and lets suppose that the time- $t$ rating class of the bond is $k$. Consider a one-period investment in this bond at $t$. Then, at time $t+h$, there is a set of possible values $\Pi_{j}(t+h, T), \forall j=1, \ldots, K+1$, since the bond may remain in its time- $t$ rating class $k$, or move to any other rating class $j$. Thus, we have

$$
E_{k}^{t}[\Pi(t+h, T) \mid \text { No Default }]=E^{t}\left[\sum_{j=1}^{K} \frac{q_{k, j}(t)}{1-\lambda_{k}(t)} \cdot \Pi_{j}(t+h, T)\right] .
$$

The expectation in RHS above is over the state-space $\left(X_{0}, \mathbf{X}\right)$. Note that $\lambda_{k}(t) \equiv q_{k, K+1}(t)$ and the sum inside the expectation is over all possible rating classes at $t+h$, conditional on no-default at $t+h$.

If the bond has defaulted in the period $(t, t+h]$, there is a cashflow at $t+h$ due to the recovery upon default. By RMV assumption (2.6), the expected cashflow is $\phi_{k}(t) E_{k}^{t}[\Pi(t+h, T)]$. Since the probability of default by $t+h$, given rating class at time $t$ is $k$, is $\lambda_{k}(t)$, the undiscounted expected value of the bond is

$$
\left(1-\lambda_{k}(t)\right) E_{k}^{t}[\Pi(t+h, T) \mid \text { No Default }]+\lambda_{k}(t) \phi_{k}(t) E_{k}^{t}[\Pi(t+h, T) \mid \text { No Default }], \forall k
$$

which is the same as

$$
\left[1-\lambda_{k}(t)+\lambda_{k}(t) \phi_{k}(t)\right] E_{k}^{t}[\Pi(t+h, T) \mid \text { No Default }], \quad \forall k
$$

By definition of $Q$, when discounted at the short rate $r(t)$, this expected cash flow must equal $\Pi_{k}(t, T)$, so we have

$$
E^{t}\left[\frac{\left[1-\lambda_{k}(t)+\lambda_{k}(t) \phi_{k}(t)\right] E_{k}^{t}[\Pi(t+h, T) \mid \text { No Default }]}{\exp \{r(t) h\} \Pi_{k}(t, T)}\right]=1, \quad \forall k .
$$

Now, using relations (2.7) and (2.5), and the definitional relation $s(t, t)=\varphi(t, t)-f(t, t)$, we get

$$
\begin{aligned}
\Pi_{k}(t, T) \cdot \exp \left\{\left[r(t)+\sum_{j=1}^{k} s_{j}(t, t)\right] h\right\} & =\exp \left\{-\sum_{i=\frac{t}{h}+1}^{\frac{T}{h}-1} \varphi_{k}(t, i h) \cdot h\right\} \text {, and } \\
E_{k}^{t}[\Pi(t+h, T) \mid \text { No Default }] & =E^{t}\left[\sum_{j=1}^{K} \frac{q_{k, j}(t)}{1-\lambda_{k}(t)} \cdot \exp \left\{-\sum_{i=\frac{t}{h}+1}^{\frac{T}{h}-1} \varphi_{j}(t+h, i h) \cdot h\right\}\right]
\end{aligned}
$$


Using the above two equations, we get the implicit equation for the drift terms $\beta(t, T)$ :

$$
E^{t}\left[\sum_{j=1}^{K} \frac{q_{k, j}(t)}{1-\lambda_{k}(t)} \exp \left\{-\sum_{i=\frac{t}{h}+1}^{\frac{T}{h}-1}\left(\varphi_{j}(t+h, i h)-\varphi_{k}(t, i h)\right) \cdot h\right\}\right]=1 .
$$

Now, writing $\varphi_{j}(t+h, i h)-\varphi_{k}(t, i h)$ as $\varphi_{j}(t+h, i h)-\varphi_{j}(t, i h)+\varphi_{j}(t, i h)-\varphi_{k}(t, i h)$, and using relations (2.1), (2.2), and (2.3), we can rewrite the above equation as

$$
\begin{aligned}
E^{t}\left[\sum_{j=1}^{K} \frac{q_{k, j}(t)}{1-\lambda_{k}(t)} \cdot \exp \left\{-\sum_{i=\frac{t}{h}+1}^{\frac{T}{h}-1}\left(\alpha(t, i h) \cdot h^{2}+\sigma(t, i h) X_{0} \cdot h^{\frac{3}{2}}\right)\right\}\right. \\
\exp \left\{-\sum_{i=\frac{t}{h}+1}^{\frac{T}{h}-1} \sum_{l=1}^{j}\left(\beta_{l}(t, i h) \cdot h^{2}+\eta_{l}(t, i h)^{\prime} \mathbf{X} \cdot h^{\frac{3}{2}}\right)\right\} \\
\left.\exp \left\{-\sum_{i=\frac{t}{h}+1}^{\frac{T}{h}-1}\left(\varphi_{j}(t, i h)-\varphi_{k}(t, i h)\right) \cdot h\right\}\right]=1 .
\end{aligned}
$$

Using the notation $\theta_{j}(t, i h)=\sum_{l=1}^{j} \beta_{l}(t, i h)$, and assuming independence of the rating transition process from the diffusion processes $\left(X_{0}, \mathbf{X}\right)$, we get $\forall t, \forall k$, at each state, a system of $K$ linear equations in $K$ unknowns $\left(x_{j}, j=1, \ldots, K\right)$ :

$$
\sum_{j=1}^{K} a_{k, j} \cdot b_{k, j} \cdot x_{j}=1
$$

where

$$
\begin{aligned}
& a_{k, j}=\frac{q_{k, j}(t)}{1-\lambda_{k}(t)} \cdot \exp \left\{-\sum_{i=\frac{t}{h}+1}^{\frac{T}{h}-1} \alpha(t, i h) \cdot h^{2}\right\} \cdot \exp \left\{-\sum_{i=\frac{t}{h}+1}^{\frac{T}{h}-1}\left(\varphi_{j}(t, i h)-\varphi_{k}(t, i h)\right) \cdot h\right\}, \\
& b_{k, j}=E^{t}\left[\exp \left\{-\sum_{i=\frac{t}{h}+1}^{\frac{T}{h}-1}\left(\sigma(t, i h) X_{0}+\sum_{l=1}^{j} \eta_{l}(t, i h)^{\prime} \mathbf{X}\right) \cdot h^{\frac{3}{2}}\right\}\right], \text { and } \\
& x_{j}=\exp \left\{-\sum_{i=\frac{t}{h}+1}^{\frac{T}{h}-1} \theta_{j}(t, i h) \cdot h^{2}\right\} .
\end{aligned}
$$

\section{B Implementation Pseudo-Code for Pricing a CSN}


/* Program to generate the HJM tree with rating transitions and default risk recursively, and then to price a Credit Sensitive Note */

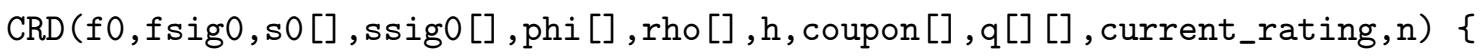

/* Note that in our example, $\mathrm{K}=2 * /$

/* $\mathrm{n}:$ number of periods $* /$

/* $\mathrm{q}$ : assumed to be the risk-neutral transition matrix $* /$

q_uuu $=0.25 *(1+$ rho[1] + rho[2] + rho[3] $)$;

q_uud $=0.25 *(1+\mathrm{rho}[1]+\mathrm{rho}[2]-\mathrm{rho}[3])$;

q_udu $=0.25 *(1-\operatorname{rho}[1]+\mathrm{rho}[2]+\mathrm{rho}[3])$;

q_udd $=0.25 *(1-\operatorname{rho}[1]+$ rho[2] - rho[3] $)$;

q_duu $=0.25 *(1-r h o[1]-r h o[2]+r h o[3])$;

q_dud $=0.25 *(1-\operatorname{rho}[1]-r h o[2]-r h o[3])$;

q_ddu $=0.25 *(1+r h o[1]-r h o[2]+r h o[3])$;

q_ddd $=0.25 *(1+\operatorname{rho}[1]-r h o[2]-r h o[3])$;

CRVAL(level,f,fsig,s[],ssig[],phi[], rating) \{

/* i, j, k, m : counters; alpha, beta : arrays for drift terms */

if (level $==n-1)\{$

result $=\exp (-\mathrm{s}[$ rating $] * \mathrm{~h}) *(1.0+\operatorname{coupon}[$ rating $]) ;$

\}

else $\{\quad / *$ level $<\mathrm{n}-1 * /$

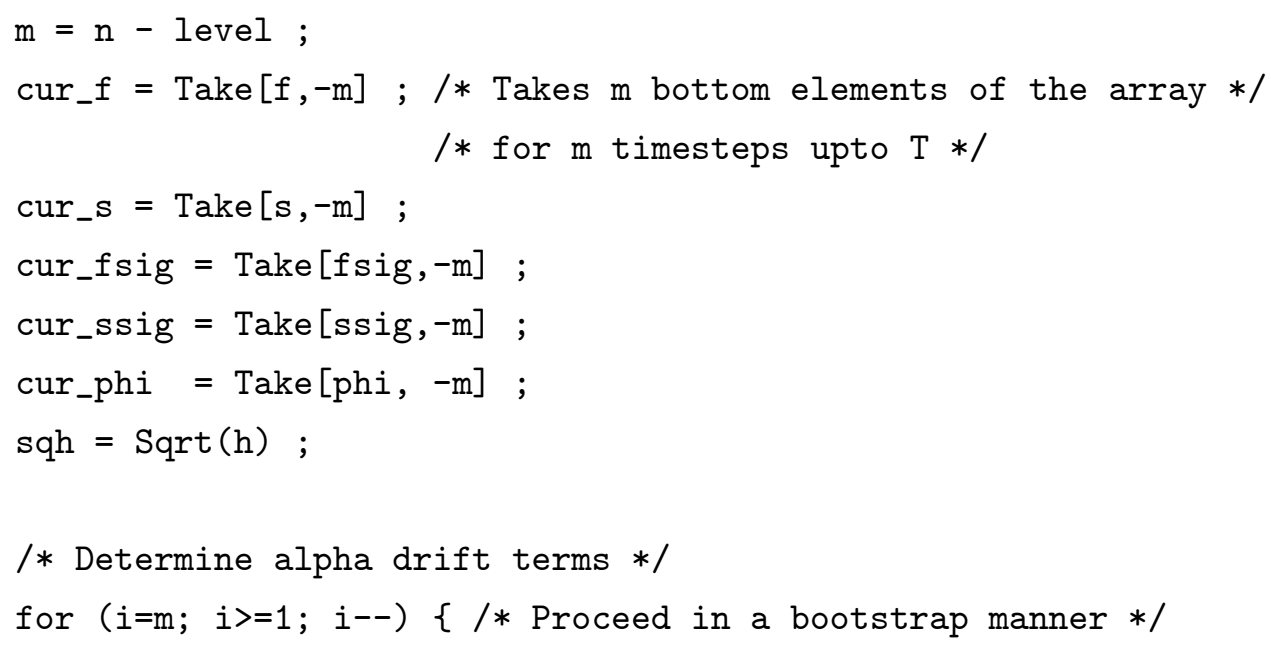




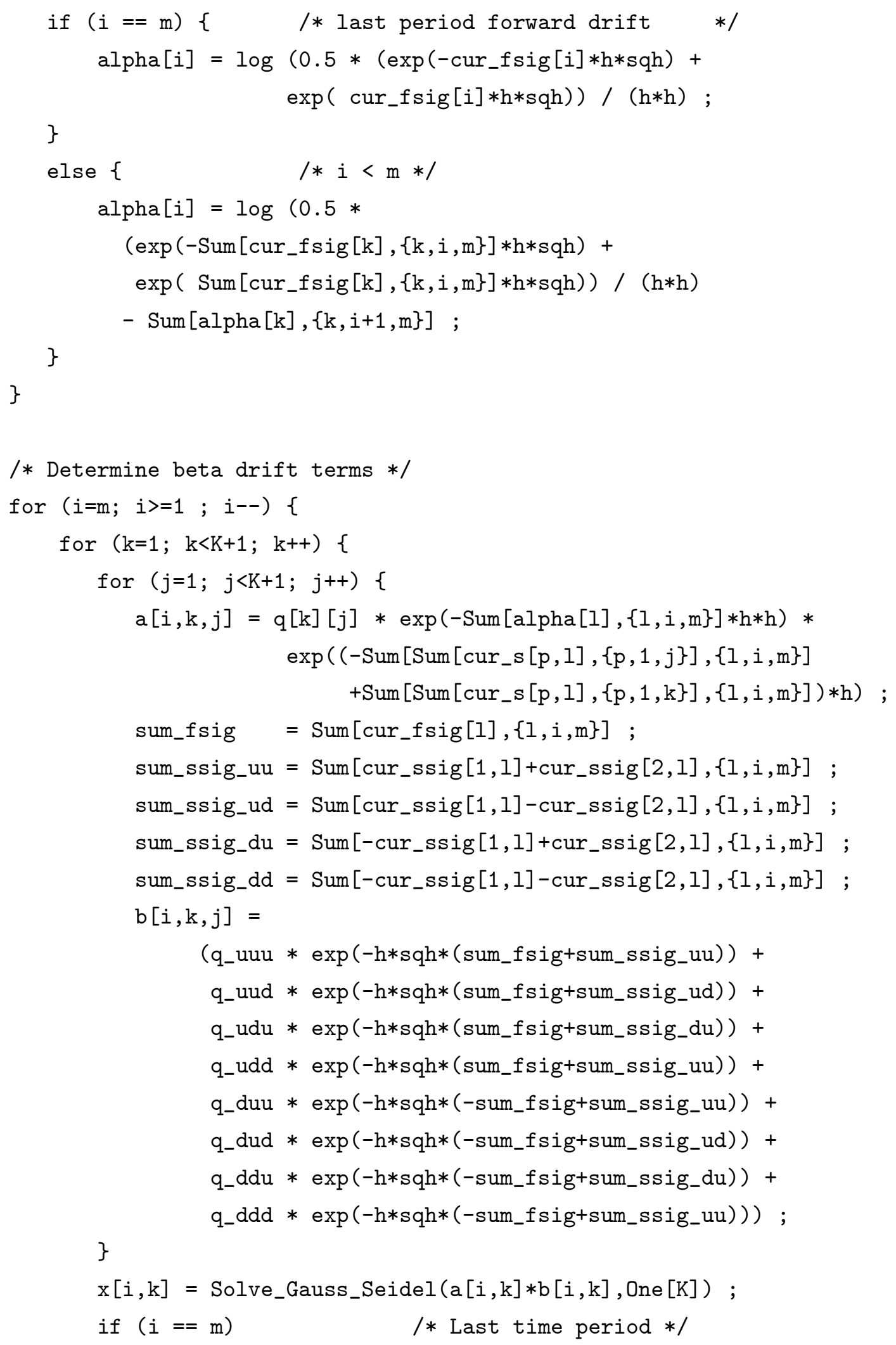




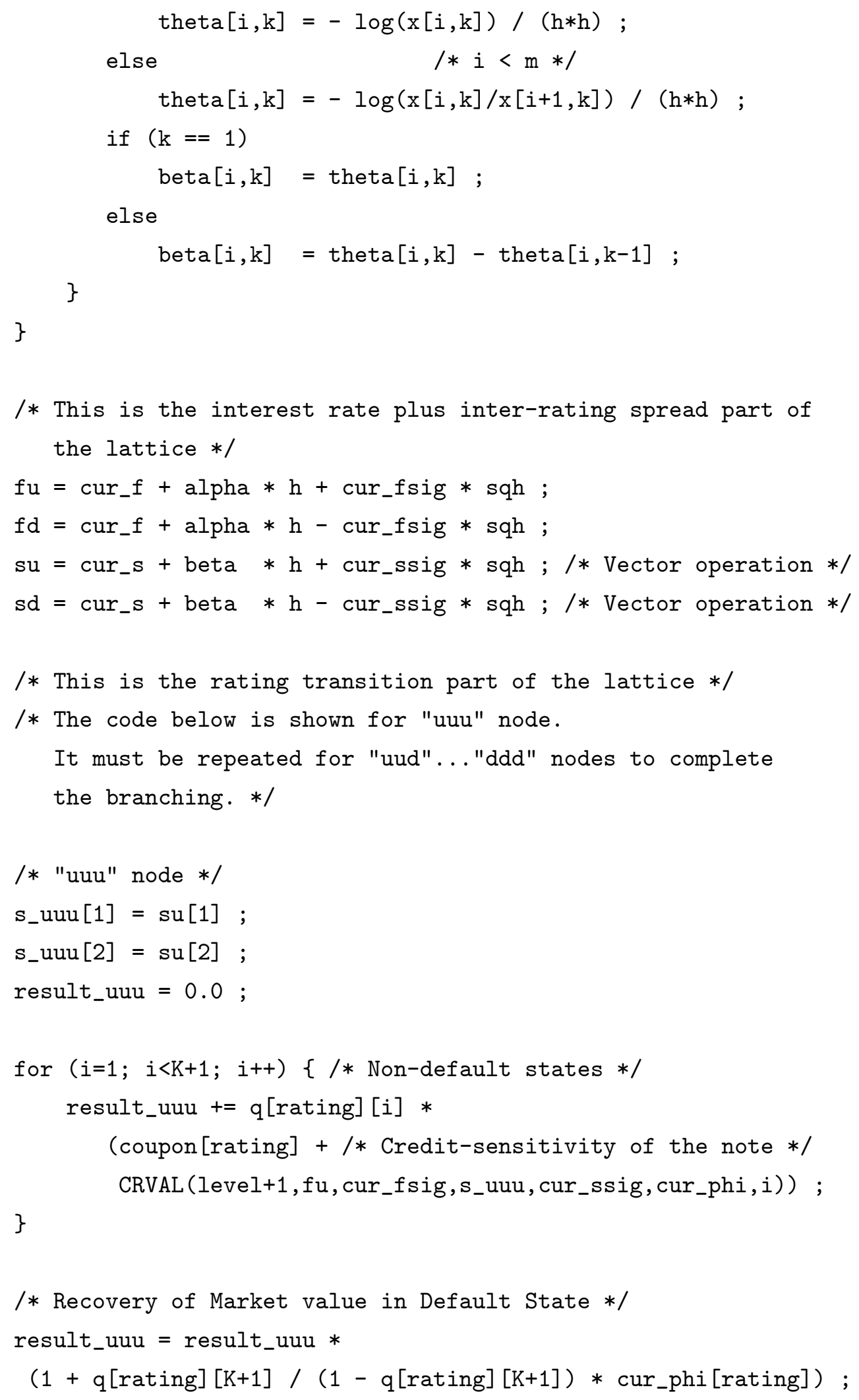




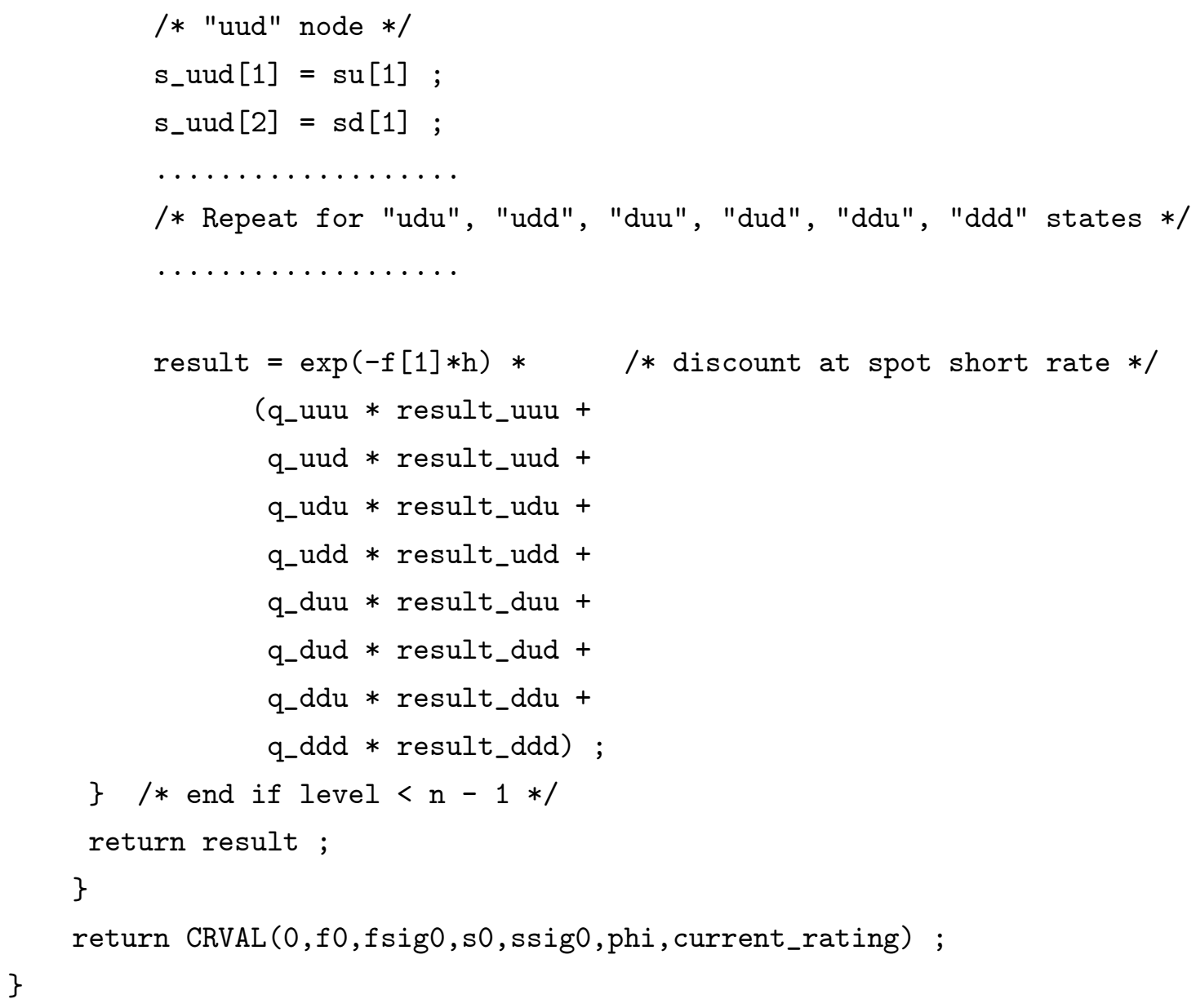

\section{References}

[1] ADLER, D., and E. ALTMAN (1998) "The Anatomy of the High Yield Bond Market," Global Corporate Bond Research, Salomon Smith Barney.

[2] ALTMAN, E., and V. KISHORE (1996) "Almost Everything you Wanted to Know About Recoveries on Defaulted Bonds," Financial Analysts Journal, Nov-Dec, 57-63.

[3] ARVANTIS, A., J. GREGORY, and J-P. LAURENT (1999) "Building Models for Credit Spreads," The Journal of Derivatives, Spring, 27-43.

[4] BIELECKI, T.R., and M. RUTKOWSKI (2000) "Multiple Ratings Model of Defaultable Term Structure," Mathematical Finance, v10(2), 125-139. 
[5] BHATTACHARYA, S., and S. MASON (1981) "Risky Debt, Jump Processes and Safety Covenants," Journal of Financial Economics, v9(3), 281-307.

[6] BLACK, F., and J. COX (1976) "Valuing Corporate Securities: Some Effects of Bond Indenture Provisions," The Journal of Finance, v31(2), 361-367.

[7] BLACK, F., E. DERMAN, and W. TOY (1990) "A One-Factor Model of Interest Rates and Its Application to Treasury Bond Options," Financial Analysts Journal, Jan-Feb, 33-39.

[8] BLACK, F., and M. SCHOLES (1973) "The Pricing of Options and Corporate Liabilities," Journal of Political Economy, v81, 637-654.

[9] CROSBIE, P. (1997) "Modeling Default Risk," KMV Corporation.

[10] DAS, S.R. (1995) "Credit Risk Derivatives," Journal of Derivatives, v2(3), 7-23.

[11] DAS, S.R. and R. SUNDARAM (2000) "A Discrete-Time Approach to Aribitrage-Free Pricing of Credit Derivatives," Management Science, v46(1), 46-62.

[12] DAS, S.R., and P. TUFANO (1996) "Pricing Credit Sensitive Debt when Interest Rates, Credit Ratings and Credit Spreads are Stochastic," Journal of Financial Engineering, v5, 161-198.

[13] DAS, S.R. (1999) "Pricing Credit Derivatives," Handbook of Credit Derivatives, eds J. Francis, J. Frost and J.G. Whittaker, 101-138.

[14] DELIANEDIS, G., and R. GESKE. (1998) "Credit Risk and Risk Neutral Default Probabilities: Information about Rating Migrations and Defaults," working paper, UCLA.

[15] DUfFEE, G. (1999) "Estimating the Price of Default Risk," Review of Financial Studies, v12(1), 197-226.

[16] DUFFEE, G. (1998) "The Relation Between Treasury Yields and Corporate Bond Yield Spreads," Journal of Finance, v53, 1998, pp. 2225-2242.

[17] DUFFIE, D. (1999) “Credit Swap Valuation," Financial Analysts Journal, Jan/Feb, 73-87.

[18] DUFFIE, D., and M. HUANG. (1996) "Swap Rates and Credit Quality," Journal of Finance, v51, 921-950.

[19] DUFFIE, D., M. SCHRODER, and C. SKIADAS. (1996) "Recursive Valuation of Defaultable Securities and the Timing of Resolution of Uncertainty," Annals of Applied Probability, v6, 1075-1090.

[20] DUFFIE, D., and K. SINGLETON (1999) "Modeling Term Structures of Defaultable Bonds," Review of Financial Studies, v12, pp. 687-720. 
[21] GESKE, R. (1977) "Valuation of Corporate Liabilities as Compound Options," Journal of Financial and Quantitative Analysis, 541-552.

[22] HARRISON, J.M. AND D.M. KREPS (1979) Martingales and Arbitrage in Multi-Period Securrities Markets, Journal of Economic Theory 20, 381-408.

[23] HARRISON, J.M. AND S.R. PLISKA (1980) Martingales and Stochastic Integrals in the Theory of continuous Trading, Stochastic Processes and their Applications 11, 215-260.

[24] HEATH, D., R.A. JARROW, and A. MORTON (1990) "Bond Pricing and the Term Structure of Interest Rates: A Discrete Time Approximation," Journal of Financial and Quantitative Analysis, v25(4), 419-440.

[25] HUANG, J. (1996) "Option to Default and Optimal Debt Service," working paper, New York University.

[26] JARROW, R., D. LANDO, and S. TURNBULL. (1997) "A Markov Model for the Term Structure of Credit Spreads," Review of Financial Studies, v10, 481-523.

[27] JARROW, R., and S. TURNBULL. (1995) "Pricing Options on Financial Securities Subject to Default Risk," Journal of Finance, v50, 53-86.

[28] KIJIMA, M. (1998) "Monotonicities in a Markov Chain Model for Valuing Corporate Bonds Subject to Credit Risk," Mathematical Finance, v8(3), 229-247.

[29] KIJIMA, M. and K. KOMORIBAYASHI (1998) "A Markov Chain Model for Valuing Credit Derivatives," Journal of Derivatives, v6(1), 97-108.

[30] KIM, I.J., K. RAMASWAMY, and S. SUNDARESAN (1989) "The Valuation of Corporate Fixed Income Securities," working paper, Wharton School, University of Pennsylvania.

[31] KIM, I.J., K. RAMASWAMY, and S. SUNDARESAN (1993) "Does Default Risk in Coupons Affect the Valuation of Corporate Bonds?: A Contingent Claims Model," Financial Management, v22, 117-131.

[32] KMV Corporation (1993) Credit Monitor Overview, San Francisco, California.

[33] LANDO, D. (1998) "Cox Processes and Credit-Risky Bonds," Review of Derivatives Research 2, 99-120.

[34] LELAND, H (1994) "Corporate Debt Value, Bond Covenants, and Optimal Capital Structure," Journal of Finance, v49, 1213-1252.

[35] LONGSTAFF, F., and E. SCHWARTZ. (1995) "A Simple Approach to Valuing Fixed and Floating Rate Debt," Journal of Finance, v50, 789-819. 
[36] MADAN, D., and H. UNAL (1998) "Pricing the Risks of Default," Review of Derivatives Research 2 , 121-60.

[37] MADAN, D., and H. UNAL (1998) "A Two Factor Hazard Rate Model for Pricing Risky Debt in a Complex Capital Structure," working paper, University of Maryland, forthcoming Journal of Financial and Quantitative Analysis.

[38] MERTON, R.C. (1974) "On the Pricing of Corporate Debt: The Risk Structure of Interest Rates," The Journal of Finance, v29, 449-470.

[39] NEILSEN, L., J. SAA-REQUEJO, and P. SANTA-CLARA (1993) "Default Risk and Interest Rate Risk: The Term Structure of Default Spreads," working paper, INSEAD, Fontainbleau, France.

[40] RAMASWAMY, K., and S. SUNDARESAN. (1986) "The Valuation of Floating Rate Instruments: Theory and Evidence," Journal of Financial Economics, 261-272.

[41] SHIMKO, D., N. TEJIMA, and D. VAN-DEVENTER (1993) "The Pricing of Risky Debt when Interest Rates are Stochastic," The Journal of Fixed-Income 3, 58-65.

[42] SCHÖNBUCHER, P.J. (1998) "Term-Structure Modeling of Defaultable Bonds," Review of Derivatives Research 2, 161-92.

[43] SKORA, R. (1998) "Credit Modeling and Credit Derivatives: Rational Modeling," working paper, Skora and Co, Inc.

[44] VASICEK, O. (1977) "An Equilibrium Characterization of the Term-Structure," Journal of Financial Economics 5, 177-88.

[45] WILSON, T. (1997) "Portfolio Credit Risk (I)," Risk, v10(9), September.

[46] WOLFRAM, S (1988) "Mathematica: A System for Doing Mathematics by Computer," AddisonWesley, California. 
Figure 1: Information generated at Each Node in the Combination of a Multi-dimensional Interest Rate plus Spreads Tree and the Rating Transitions

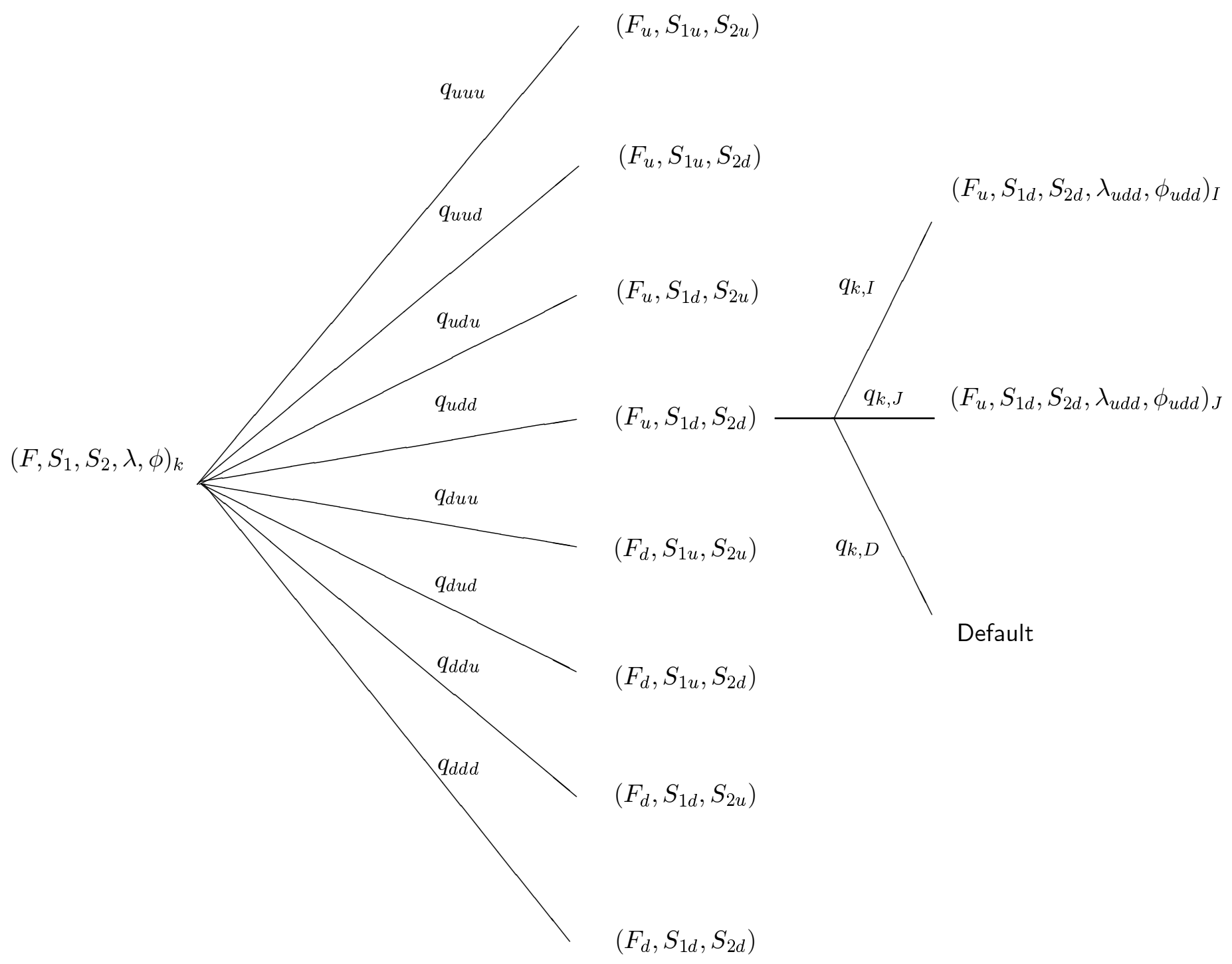

The figure illustrates how the multi-dimensional tree of interest rate and inter-rating spread processes combines with the rating transitions to yield the complete lattice. The left part of the braching shows the eight nodes that emanate from a starting rating class $k$, depending upon the realizations of the binomial variates $\left(X_{0}, X_{1}, X_{2}\right)$. The right part of the branching shows for one of these eight nodes, in particular the up-down-down node, the rating transitions to the three possible states $I, J$, and $D$. The probabilities $q_{u u u}, \ldots, q_{d d d}$ for the interest rate plus spreads lattice are given by the equation (5.1), whereas the probabilities for the rating transitions, $q_{k, I}, q_{k, J}$, and $q_{k, D}$, are given by the rating transition matrix at the corresponding node. Note that Default is an absorbing state. 
Table 1: Tree for Forward Risk-free Rate and Inter-rating Spreads

This table shows a tree of forward risk-free rate and forward inter-rating spreads, calibrated as per the parameter specification in the text. The calibration of the risk-neutral drifts is done using the results in Proposition 3.1 and Proposition 3.2.

\begin{tabular}{|c|c|c|c|c|c|c|c|c|c|c|}
\hline & \multicolumn{2}{|l|}{$t=0$} & \multicolumn{4}{|c|}{$\mathrm{t}=0.5$} & \multicolumn{4}{|c|}{$\mathrm{t}=1.5$} \\
\hline & & & & & & & $u u$ & 0.092017 & 0.039013 & 0.056522 \\
\hline & & & $u u$ & 0.075504 & 0.023003 & 0.043004 & $u d$ & 0.092017 & 0.027013 & 0.050522 \\
\hline & & & & 0.086013 & 0.033007 & 0.053515 & $d u$ & 0.080017 & 0.039013 & 0.056522 \\
\hline & & & & & & & $d d$ & 0.080017 & 0.027013 & 0.050522 \\
\hline & & & & & & & $u u$ & 0.092017 & 0.033013 & 0.049522 \\
\hline & & & $u d$ & 0.075504 & 0.017002 & 0.037004 & $u d$ & 0.092017 & 0.021013 & 0.043522 \\
\hline$F$ & $S_{I}$ & $S_{J}$ & & 0.086013 & 0.027007 & 0.046515 & $d u$ & 0.080017 & 0.033013 & 0.049522 \\
\hline 0.06 & 0.02 & 0.04 & & & & & $d d$ & 0.080017 & 0.021013 & 0.043522 \\
\hline 0.07 & 0.02 & 0.04 & & & & & & & & \\
\hline 0.08 & 0.03 & 0.05 & & & & & $u u$ & 0.080017 & 0.039013 & 0.056522 \\
\hline & & & $d u$ & 0.064504 & 0.023002 & 0.043004 & $u d$ & 0.080017 & 0.027013 & 0.050522 \\
\hline & & & & 0.074013 & 0.033007 & 0.053515 & $d u$ & 0.068017 & 0.039013 & 0.056522 \\
\hline & & & & & & & $d d$ & 0.068017 & 0.027013 & 0.050522 \\
\hline & & & & & & & $u u$ & 0.080017 & 0.033013 & 0.049522 \\
\hline & & & $d d$ & 0.064504 & 0.017002 & 0.037004 & $u d$ & 0.080017 & 0.021013 & 0.043522 \\
\hline & & & & 0.074013 & 0.027007 & 0.046515 & $d u$ & 0.068017 & 0.033013 & 0.049522 \\
\hline & & & & & & & $d d$ & 0.068017 & 0.021013 & 0.043522 \\
\hline
\end{tabular}

Table 2: Tree for Risk-free, Investment Grade, and Speculative Grade Zero Bond Prices

This table shows a tree of zero bond prices for risk-free, investment grade, and speculative grade bonds. The underlying forward rate tree is as in Table 1 and its calibration is done using the results in Proposition 3.1 and Proposition 3.2.

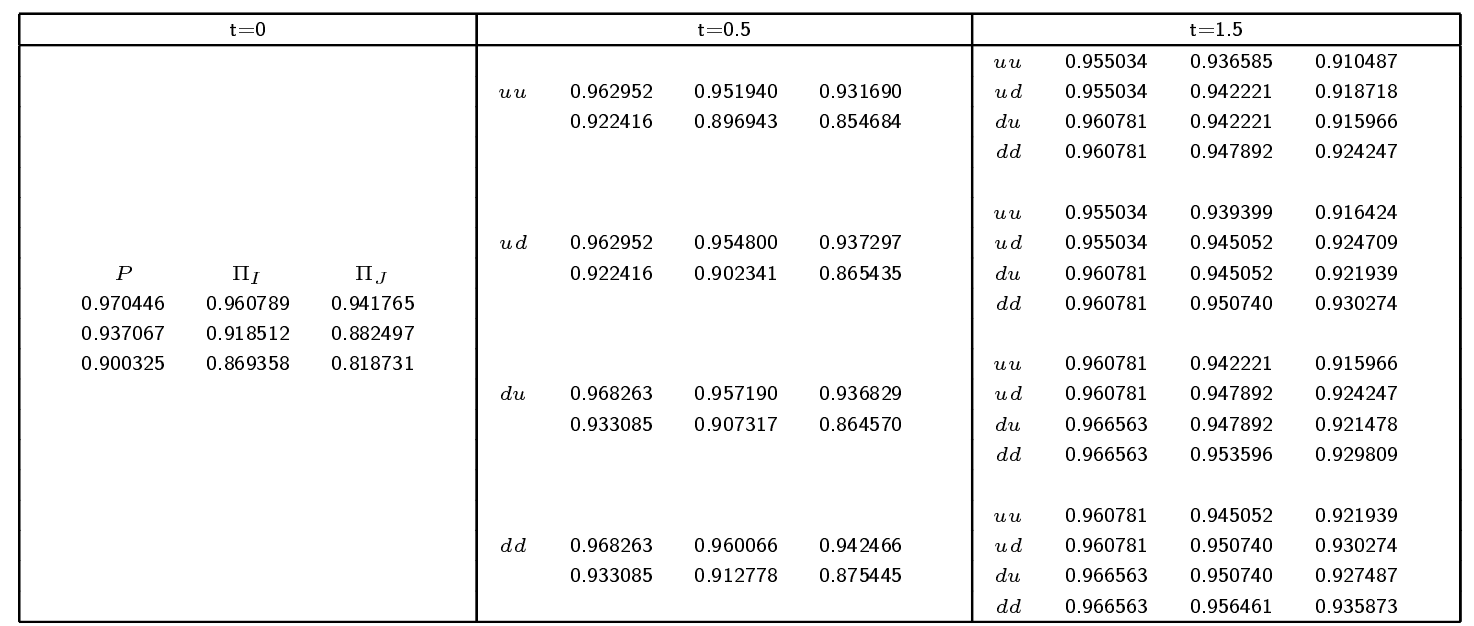


Table 3: Tree for Credit Sensitive Note Prices

This table shows a tree of prices for the credit sensitive note that is to mature in 1.5 years and has the coupon schedule: $c_{I}=0.04675$ and $c_{J}=0.06375$.

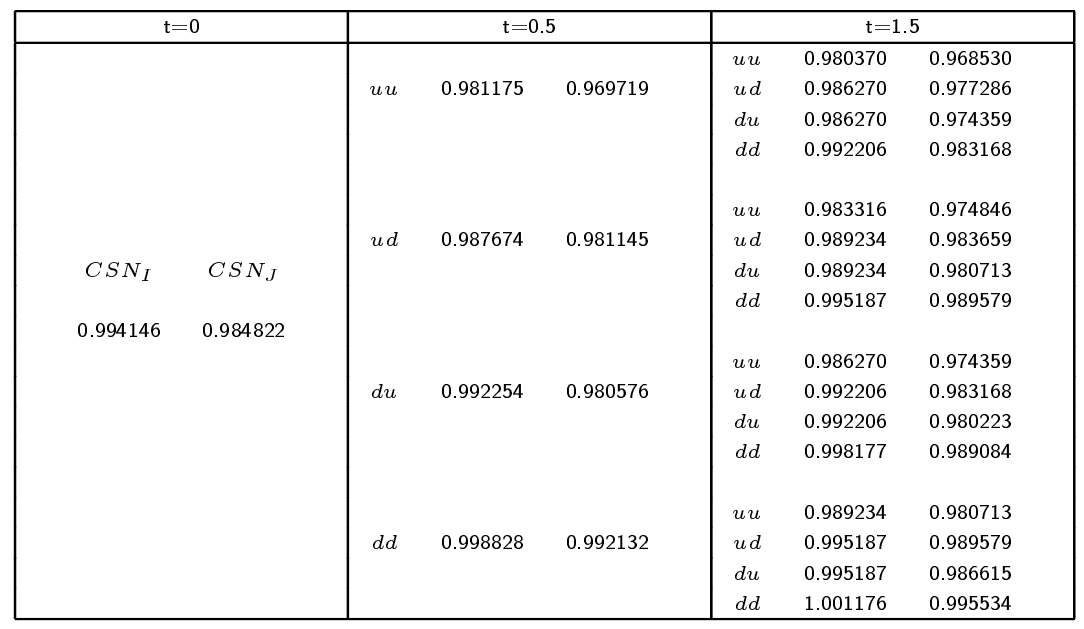

Table 4: Tree for Credit Insensitive Note Prices

This table shows a tree of prices for the credit insensitive note that is to mature in 1.5 years and has a coupon $c=0.04675$. It is identical to the credit sensitive note considered in Table 3 except that its coupon is not linked to the rating of the underlying credit.

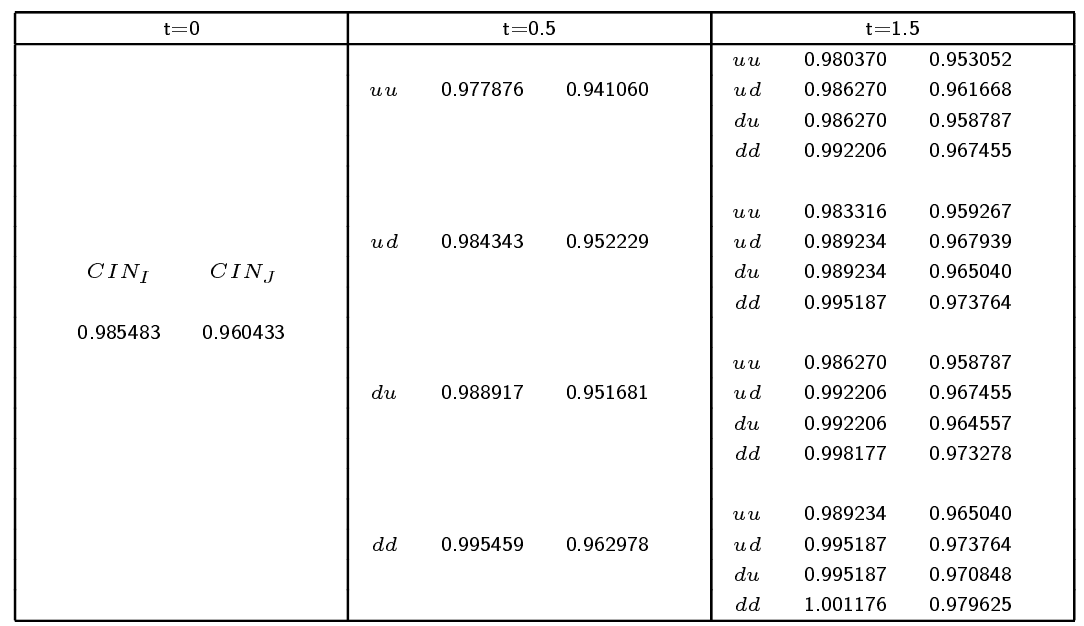

